\title{
Shear fracture tests of concrete
}

\author{
Z. P. Bažant \\ Professort of Civil Engineering and Center Director \\ Center for Concrete and Geomaterials, Northwestern University, \\ Evanston, Illinois 60201, USA.
}

\section{P. A. Pfeiffer}

Graduate Research Assistant; presently Resident Student Associate, Argonne National Laboratory

Symmetrically notched beam specimens of concrete and mortar, loaded near the notches by concentrated forces that produce a concentrated shear force zone, are tested to failure. The cracks do not propagate from the notches in the direction normal to the maximum principal stress but in a direction in which shear stresses dominate. Thus, the failure is due essentially to shear fracture (Mode In). The crack propagation direction seems to be governed by maximum energy release rate. Tests of geometrically similar specimens yield maximum loads which agree with the recently established size effect law for blunt fracture, previously verified for tensile fracture (Mode $)$. This further implies that the energy required for crack growth increases with the crack extension from the notch. The $R$-curve that describes this increase is determined from the size effect. The size effect also yields the shear fracture energy, which is found to be about 25-times larger than that for Mode I and to agree with the value predicted by the crack band model. The fracture specimen is simple to use but not perfect for shear fracture because the deformation has a symmetric component with a non zero normal stress across the crack plane. Nevertheless, these disturbing effects appear to be unimportant. The results are of interest for certain types of structures subjected to blast, impact, earthquake, and concentrated loads.

\section{INTRODUCTION}

Cracks in concrete or mortar have been generally assumed to propagate in the direction normal to the maximum principal stress, which represents the tensile, opening fracture mode, designated as Mode I. This type of cracking has been observed even for the failure of many structures loaded in shear, e.g., the diagonal shear failure of beams, the punching shear failure of slabs, the torsional failure of beams, the shear failure of panels, etc. Ingraffea [1] recently showed that in a shear-loaded beam with a starter notch in the Mode II fracture direction the crack does not propagate in this direction but runs to the side in the direction normal to the maximum principal stress. Thus, it has been thought that shear fracture does not exist, and the bon mot "shear fracture is a sheer nonsense" has been heard in some recent lectures.

Shear fractures have nevertheless been experienced. For example, reinforced concrete slabs loaded by an intense short-pulse blast often fail by shearing off at the support along a crack normal to the slab. Penetration of projectiles into concrete may apparently also involve shear-produced cracks. The possibility of shearproduced fractures is of considerable concern for all problems where the shear resistance of cracks due to surface roughness (aggregate interlock) is of concern, as it is, e. g., for seismic loading of nuclear containments or tall building structures. In these problems it is assumed that the shear-loaded cracks have previously somehow formed due to tensile loading (Mode I loading). More likely, however, the preformed tensile cracks would be only partial, discontinuous, and the final continuous cracks would be produced by the shear loading itself. Therefore, a program to investigate the shear fracture of concrete has been undertaken at Northwestern University. The first preliminary report was given at a recent symposium [25] and a detailed presentation of the results is the purpose of this paper.

\section{TEST SPECIMENS}

The test specimens were beams of constant rectangular cross section and constant length-to-depth ratio 8:3 (see fig. 1). To determine the size effect, a crucial aspect 


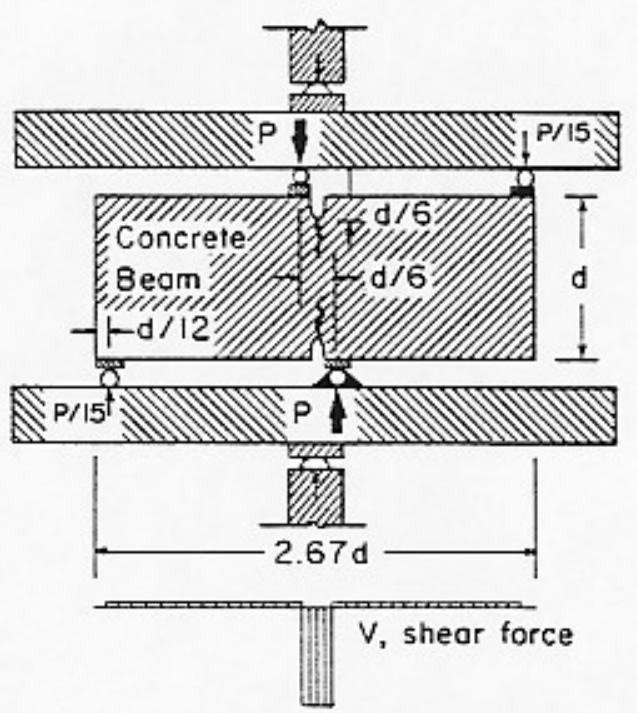

Fig. 1. - Geometry of test specimen and shear force diagram.

of fracture mechanics, geometrically similar specimens of various depths, $d=1.5,3,6$ and 12 in. (fig. 2), were tested. The specimens of all sizes were cast from the same batch of concrete or mortar, and their thicknesses $b$ were the same; $b=1.5$ in.

For comparison of specimens of different sizes, the choice of their thicknesses is a subtle question which has no clear-cut answer. The question arises with respect to the effect of the probable variation of fracture energy along the crack edge across the thickness. This variation is principally due to two effects: (1) The fact that the crack front in the interior of the specimen is essentially in plane strain, while near the surface it is essentially in plane stress, which causes for elastic behavior an additional stress singularity at the surface termination of the crack edge [2]; and (2) the fact that nonplanar deformation at crack front near the surface may be caused by failures along planes nonorthogonal to the specimen sides, similarly to the shear-lip phenomenon in plastic fracture of metals ([3], [4], [5]). The former effect would prevail for structures very large compared to the aggregate size, which would basically follow linear fracture mechanics. The latter effect seems to be more important for structures of normal sizes because the size of the fracture process zone affected by the surface would be proportional to the aggregate size and independent of the specimen size. Therefore, the latter effect was deemed to be more important, and this was the reason for choosing the same thickness for specimens of all sizes, ensuring the same thickness-toaggregate size ratio.

A pair of symmetric notches, of depth $d / 6$ and thickness $2.5 \mathrm{~mm}$ (same thickness for all specimen sizes) was cut with a diamond saw into the hardened specimens. (Compared to the specimen with a one-sided notch used before, the symmetrically notched specimen, in which two cracks propagate simultaneously, is simpler to analyze). The specimens were cast with the side of depth $d$ in a vertical position, using a concrete mix with water-cement ratio 0.6 and cement-sand-gravel ratio of $0: 2: 2$ (all by weight). The maximum gravel size was $d_{a}=0.5$ in. $(12.7 \mathrm{~mm})$, and the maximum sand grain size was 0.19 in. ( $4.83 \mathrm{~mm})$. Mineralogically, the aggregate consisted of crushed limestone and siliceous river sand. The aggregate and sand were air-dried prior to mixing. Portland cement C150, ASTM Type I, with no admixtures, was used.

To extend the range of relative specimen sizes $d / d_{a}$ and determine the effect of the maximum aggregate size, a second series of specimens was made of mortar, with water-cement ratio of 0.5 and cement-sand ratio of $1: 2$. The same sand as for the concrete specimens was used, the gravel being omitted. Thus, the maximum aggregate size for the mortar specimens was $d_{a}=0.19$ in. $(4.83 \mathrm{~mm})$. The water-cement ratio differed from that for concrete specimens in order to achieve approximately the same workability.

Companion cylinders 3 in. $(76.2 \mathrm{~mm})$ in diameter and 6 in. $(152.4 \mathrm{~mm})$ in length were cast from each batch of concrete or mortar to ascertain the compression strength. After standard 28-day moist curing, the mean compression strength was $f_{c}^{\prime}=5,500$ psi $(37.9 \mathrm{MPa})$ with standard deviation S.D. $=125$ psi $(0.86 \mathrm{MPa})$ for the concrete specimens, and $7,100 \mathrm{psi}(49.0 \mathrm{MPa})$ with S.D. $=107$ psi $(0.74 \mathrm{MPa})$ for the mortar specimens (each value determined from 3 cylinders).

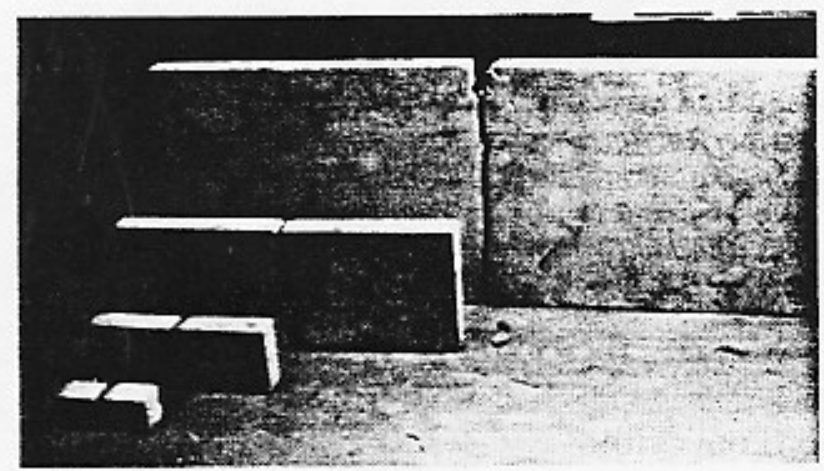

Fig. 2. - Photograph of specimens of various sizes used, taken after fracture.

The specimens were removed from the plywood forms after 1 day and were subsequently cured for 28 days until the moment of the test, in a moist room of $95 \%$ relative humidity and $78 \mathrm{~F}\left(25.6^{\circ} \mathrm{C}\right)$ temperature. Three identical specimens were cast for each type of test.

All specimens were tested in a 10 -ton $(89 \mathrm{kN})$ servocontrolled closed-loop MTS testing machine (fig. 3). The laboratory environment had relative humidity about $65 \%$ and temperature about $78 \mathrm{~F}\left(25.6^{\circ} \mathrm{C}\right)$, and the specimens were exposed to this environment approximately 3 hours before the start of the test.

The shear loading was produced by a system of steel beams shown in figures 1 and 4, which applied concentrated vertical loads onto the specimen. Three of the loads were applied through rollers, and one through a hinge, which produced a statically determinate support arrangement. The steel surfaces were carefully machined so as to minimize the friction on the rollers. 


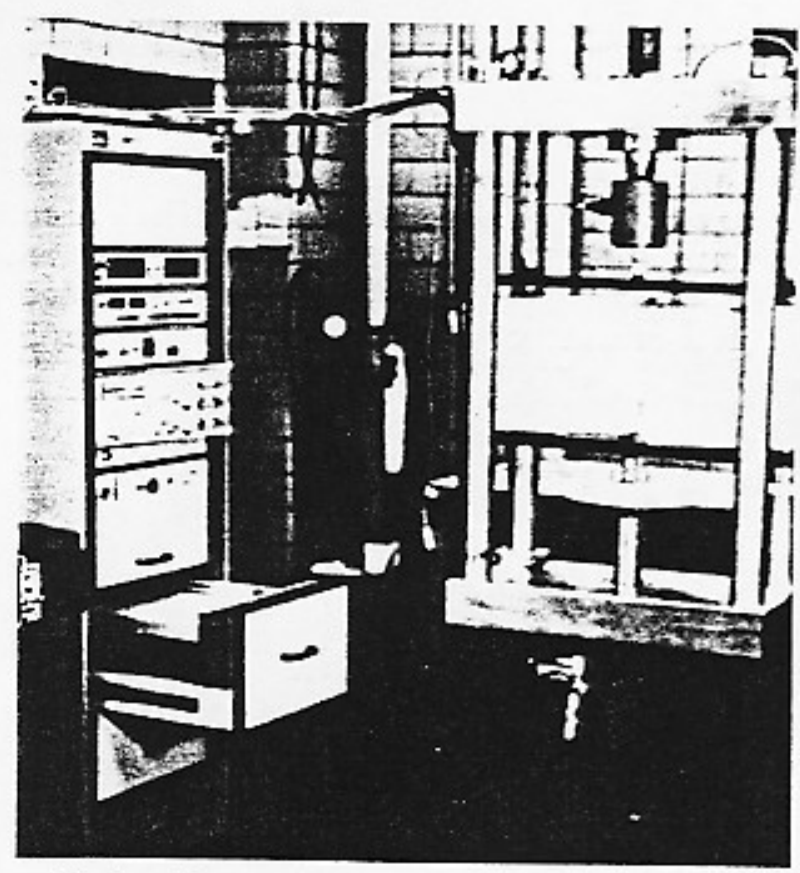

Fig. 3. - Testing machine with the 12 in. specimen after test.

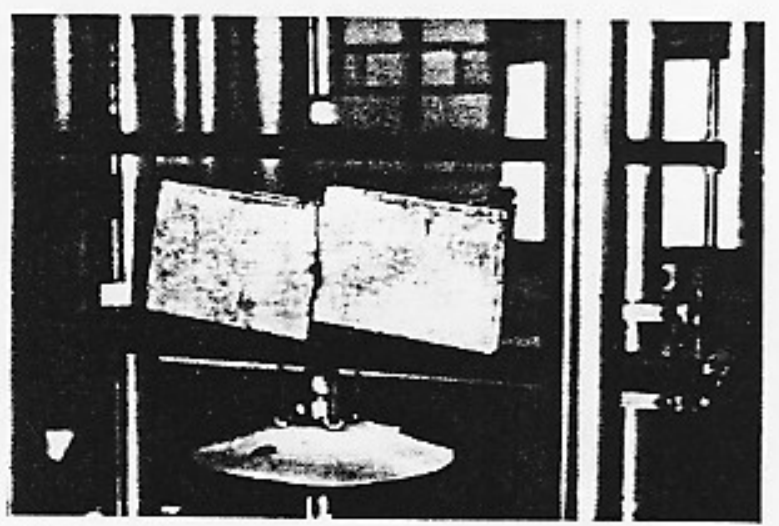

Fig. 4. - Photograph of a specimen of 6 in. depth after fracture.

The distribution of shear force $V$ in the vertical cross sections, produced by this load arrangement, is shown in figure 1 . Note that the loads were applied relatively close to the notches, so as to produce a narrow region of a high shear force. However, the loads could not be too close to the notch, or else the concrete under the support would shear off locally before the overall shear fracture could be produced. To prevent this from happening, the load-distributing steel plate under the roller could not be too small, and after some experimentation a suitable size of the support plate was determined. For the four specimen sizes, the support plates under the rollers and the hinge had the widths of $0: 25$, $0.5,1$ and 2 in. $(6.35,12.7,25.4$ and $50.8 \mathrm{~mm})$. The distance of the loads from the notch axis was always kept as $d / 12$. The thickness of all loading plates was 0.25 in. $(6.35 \mathrm{~mm})$.

The specimens were tested at constant displacement rate of the machine. For each specimen size the displacement rate was selected so as to achieve the maximum load in about 5 minutes ( \pm 30 seconds). (In retrospect, however, it seems it might have been better for mutual comparisons to choose displacement rates such that the rate of propagation of the crack front would be about the same for all specimen sizes, since this would come nearer to eliminating from the comparisons for different specimen sizes the strain rate and viscoelastic effects in the fracture process zone.)

\section{TEST RESULTS}

The cracks were found to propagate as shown in figure 4. This proves that shear fracture exists, i.e., the crack can propagate in Mode II. Microscopically, of course, the shear fracture is likely to form as a zone of inclined tensile microcracks which only later connect by shearing.

The presently observed crack direction contrasts with that observed by Ingraffea [1] in his test sketched in figure $5 a$. This test differed by its wider separation of the loading points. For comparison the present type of test was also repeated with a wider separation of the loading points. In that case the cracks propagated from the notch tip basically in the direction normal to the maximum principal stress, same as observed by Ingraffea (see fig. $5 b$ ). In both the present type of test ( fig. 1) and the tests with the wide shear zone (fig. $5 a, b$ ) the stress fields near the fracture front are similar. So the crack somehow senses the stress field remote from the cracks, and responds to it. Consequently, the stress field near the fracture front, as well as the strain and strain energy density fields near the fracture front, does not govern the direction of fracture propagation. What is then the governing law?

The answer is that a Mode I crack propagating sideway from the notch tip would, for the present type of test with a narrow shear force zone, quickly run into a low stress zone of the material, and would, therefore, release little energy. On the other hand, a
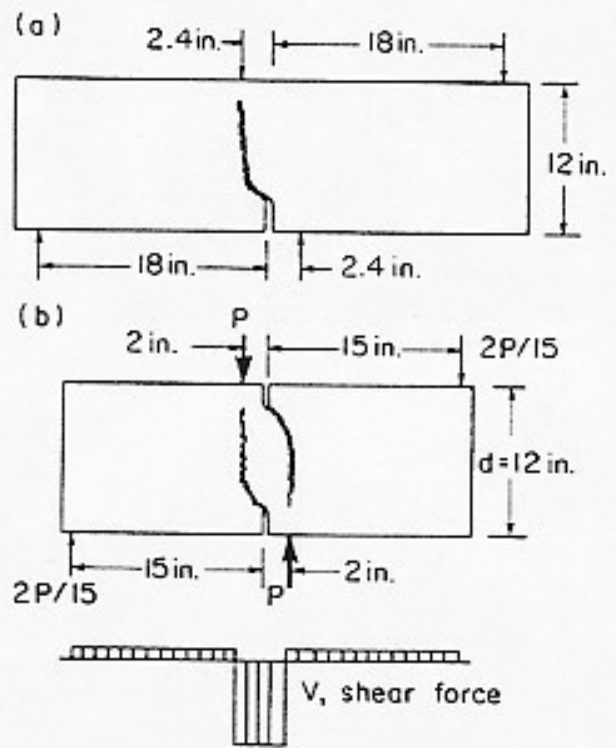

Fig. 5. - Crack path observed in notched beams with a wide zone of shear force. 
vertically running crack (Mode II) continues to remain in the highly stressed zone of the material, and can, therefore, cause a large release of strain energy. This appears to confirm that the fracture propagation direction is governed by the criterion of the maximum energy release rate. This criterion has been known in theoretical fracture mechanics and is in fact a direct consequence of the basic laws of thermodynamics.

The conclusion that the criterion of maximum energy release rate should govern the direction of crack propagation is confirmed by the finite element studies reported by Pfeiffer, Bažant, Pan, and Marchertas ([6]-[9]). In these studies, the crack band model was used, and among all finite elements adjacent to the crack band front the crack band was advanced into that element for which the energy release from the finite element system was maximum. These finite element simulations indicated the crack band to propagate sideway when the shear force zone was wide ( fig. $5 b$ ), and vertically when the shear force zone was narrow (fig. 1), which is in agreement with the observed directions of crack propagation.

The most important information from fracture tests is the maximum load measured. Its values are given in table I for all specimens of all sizes, along with the mean values.

TABLE I

MEASURED MAXIMUM LOADS

\begin{tabular}{|c|c|c|c|c|c|}
\hline \multirow{2}{*}{$\begin{array}{l}\text { Type } \\
\text { of } \\
\text { test }\end{array}$} & \multirow{2}{*}{$\begin{array}{l}\text { Depth } \\
d \\
\text { (in) }\end{array}$} & \multicolumn{3}{|c|}{$\underset{\text { (lb) }}{\text { Maximum load } P,}$} & \multirow{2}{*}{$\begin{array}{c}\text { Mean } \\
\stackrel{p}{(\text { lb) }}\end{array}$} \\
\hline & & 1 & 2 & 3 & \\
\hline Mode II Concrete. & $\begin{array}{r}1.5 \\
3.0 \\
6.0 \\
12.0\end{array}$ & $\begin{array}{l}1,399 \\
2,813 \\
5,341 \\
9,987\end{array}$ & $\begin{array}{r}1,484 \\
2,837 \\
5,621 \\
10,067\end{array}$ & $\begin{array}{r}1,494 \\
3,033 \\
5,631 \\
10,177\end{array}$ & $\begin{array}{r}1,459 \\
2,894 \\
5,531 \\
10,077\end{array}$ \\
\hline Mode II Mortar. & $\begin{array}{r}1.5 \\
3.0 \\
6.0 \\
12.0\end{array}$ & $\begin{array}{l}1,719 \\
3,221 \\
5,321 \\
9,277\end{array}$ & $\begin{array}{l}1,754 \\
3,321 \\
5,441 \\
9,777\end{array}$ & $\begin{array}{r}1,774 \\
3,371 \\
5,591 \\
10,077\end{array}$ & $\begin{array}{l}1,749 \\
3,304 \\
5,451 \\
9,710\end{array}$ \\
\hline Mode I Concrete. & $\begin{array}{r}1.5 \\
3.0 \\
6.0 \\
12.0\end{array}$ & $\begin{array}{r}405 \\
677 \\
990 \\
1,738\end{array}$ & $\begin{array}{r}408 \\
706 \\
1,040 \\
1,739\end{array}$ & $\begin{array}{r}417 \\
711 \\
1,096 \\
1,773\end{array}$ & $\begin{array}{r}410 \\
698 \\
1,042 \\
1,750\end{array}$ \\
\hline Mode I Mortar. . & $\begin{array}{r}1.5 \\
3.0 \\
6.0 \\
12.0\end{array}$ & $\begin{array}{r}456 \\
703 \\
1,005 \\
1,484\end{array}$ & $\begin{array}{r}508 \\
752 \\
1,059 \\
1,582\end{array}$ & $\begin{array}{r}543 \\
777 \\
1,104 \\
1,588\end{array}$ & $\begin{array}{r}502 \\
744 \\
1,056 \\
1,551\end{array}$ \\
\hline
\end{tabular}

$1 \mathrm{lb}=4,448 \mathrm{~N} ; 1 \mathrm{in}=25.4 \mathrm{~mm}$.

\section{SIZE EFFECT AND FRACTURE ENERGY}

The structural size effect, a salient aspect of fracture mechanics, is observed when geometrically similar structures of different characteristic dimensions $d$ are compared. This effect can be described in terms of the nominal stress at failure, defined as $\sigma_{N}=P / b d$ where $P=$ load at failure (maximum load) and $b=$ structure thickness. While according to the strength or yield criteria used in plastic limit design or elastic allowable stress design, $\sigma_{N}$ is independent of structure size $d$, in fracture mechanics $\sigma_{N}$ decreases as the structure size increases. This is because fracture mechanics is based on an energy criterion instead of a strength criterion.

Based on the approximate but apparently quite reasonable hypothesis that the energy release caused by fracture is a function of both the crack length and the area traversed by the fracture process zone, it has been shown by dimensional analysis and similitude arguments that, for geometrically similar structures or specimens ([10], [11], [12]):

$\sigma_{N}=B f_{t}^{\prime}\left[1+\left(\frac{d}{\lambda_{0} d_{a}}\right)^{r}\right]^{-1 / 2 r}$,

in which $f_{t}$ is the direct tensile strength of concrete, $d_{a}$ is the maximum aggregate size, and $B$ and $\lambda_{0}$ and $r$ are empirical parameters characterizing the shape of the structure or specimen. According to the size effect law, the plot of $\log \sigma_{N}$ vs. $\log \left(d / d_{a}\right)$ represents a gradual transition from a horizontal line representing the strength criterion (i. e., $\sigma_{N}$ proportional to strength $f_{i}$ ) to a straight line of slope $-1 / 2$ representing the energy criterion of the classical, linear elastic fracture mechanics (i. e., $\sigma_{N}$ proportional to $d^{-1 / 2}$ ).

To calibrate the size effect law once its validity has already been established requires specimens whose sizes differ no less than $1: 3$. However, to verify the validity of the size effect law one needs a much broader range of sizes, at least $1: 10$. This necessitates inclusion of large specimens in the test program. The smallest specimen is chosen as small as possible for the given size of aggregate. This is the reason for choosing the depth of the smallest specimen to be only $3 d_{a}$. The largest practicable specimen for the available testing machine was then of depth $d=24 d_{a}=12$ in. $(304.8 \mathrm{~mm})$. For concrete, however, this size is not large enough to verify the size effect law (equation 1), since the last data points for concrete in figure $7 a$ lie too far from the limiting inclined straight line of slope $-1 / 2$ corresponding to linear elastic fracture mechanics. This was the main reason for adding a second series of mortar specimens, which makes it possible to extend substantially the range of relative sizes $d / d_{a}$ without having to test still much larger specimens. Even though some additional error is no doubt introduced due to the differences between mortar and concrete other than those due to aggregate size $d_{a}$.

Equation 1 is limited to specimens made of the same material, and in particular to specimens with the same maximum aggregate size $d_{a}$. If specimens with significantly different $d_{a}$ are compared, $f_{t}$ in equation 1 must be considered as a variable; according to Bažant [26] :

$f_{t}=f_{t}^{0}\left(1+\sqrt{c_{0} / d_{a}}\right)$,

in which $f_{t}^{0}$ and $c_{0}$ are empirical constants. The last term of equation 2 has the same form as the well-known Petch's formula for the yield stress of polycrystalline metals (with grain size $d_{a}$ ) but has been derived from fracture mechanics rather than dislocation theory.

The size effect law is verified, within the limits of inevitable statistical scatter, by all available Mode I 


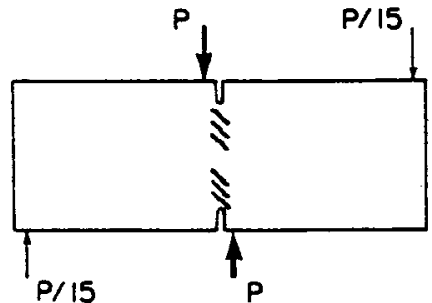

Fig. 6. - Assumed band of tensile microcracks at the fracture front.
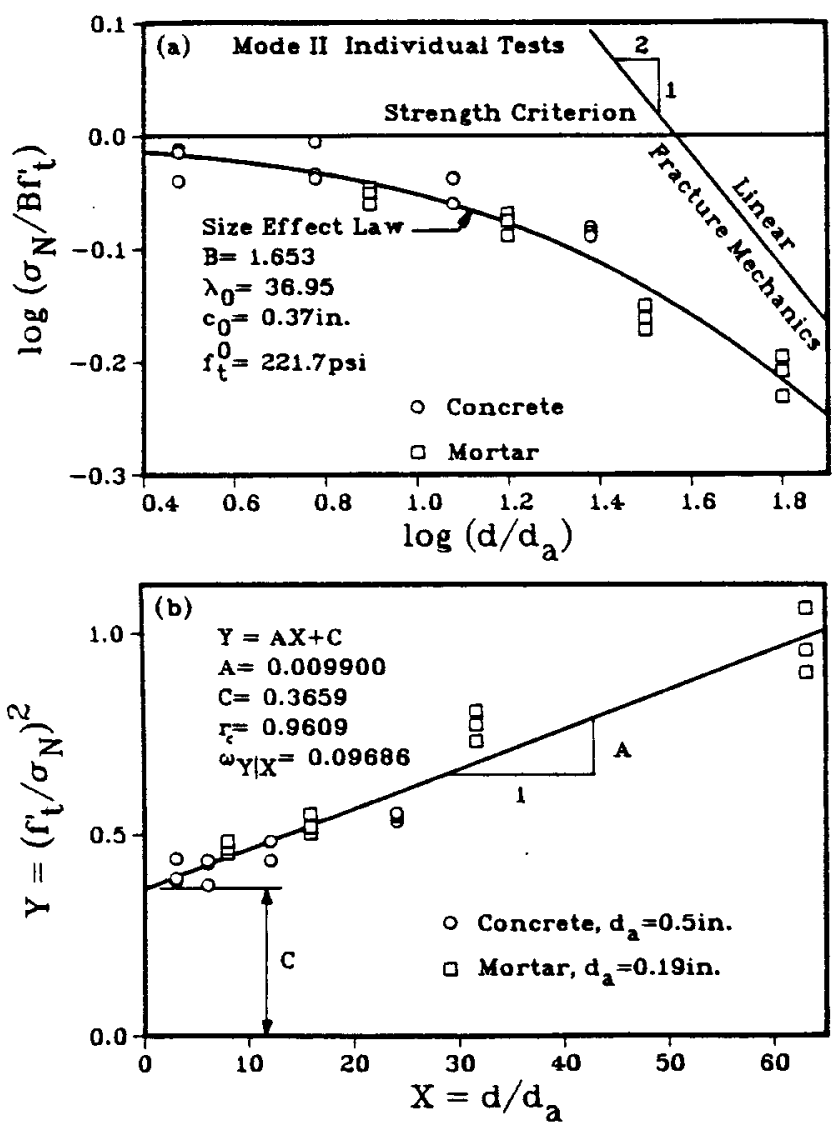

Fig. 7. - Mode II individual test results for shear fracture of concrete and mortar shown in the size effect plot and the transformed linear regression plot.

fracture tests of concrete and mortar [14]. Moreover, the size effect law has also been shown applicable to the diagonal shear failure of longitudinally reinforced beams without stirrups [12], and is probably applicable to all the brittle types of failure of reinforced concrete structures. Does the size effect law also apply to shear fracture?

The measured maximum load values show that it does. They are plotted in figure 7 as the data points, while the size effect law is plotted as the smooth curve, and a good agreement is apparent. If $c_{0}$ is given, parameters $B$ and $\lambda_{0}$ of the size effect law can be easily obtained by the linear regression plot in figure $7 b$ because equation 1 can be rearranged as $Y=A X+C$ where $X=d / d_{a}, \quad Y=\left(f_{t}^{f} / \sigma_{s}\right)^{2}, C=1 / B^{2}, \quad A=1 /\left(\lambda_{0} B^{2}\right)$. This means that $B=1 / \sqrt{C}, \lambda_{0}=1 /\left(A B^{2}\right)$ where $A$ represents the slope of the straight regression line in figure
$7 b$, and $C$ represents its intercept with axis $Y$. Parameter $c_{0}$ is determined by choosing various values of $c_{0}$ and calculating for each of them the values of $B$ and $\lambda_{0}$ by linear regression. For each $c_{0}$, the sum of squared deviations $\left(Y-Y_{\text {test }}\right)$ of the data points from the regression line is also calculated. Then one can consider this sum as a function of $c_{0}$ and determine for which $c_{0}$ this function attains its minimum.

An advantage of the regression plot is that it also yields statistics of the errors, i.e., of the deviations of the measured data points from the size effect law. According to figure 7, these deviations appear as random rather than systematic, and their coefficient of variation is found to be $\omega_{Y \mid X}=0.0969$, which is as quite acceptable for a heterogeneous material with statistical properties such as concrete. An unbiased estimate is $\omega$ $Y \mid X=\left\{\left[\sum\left(Y-Y_{\text {test }}\right)^{2}\right] /(N-2)\right\}^{1 / 2} / \bar{Y}$ where $Y-Y_{\text {test }}$ are the deviations of data points from the regression line, $N$ is the number of all data points, and $\vec{Y}=\left(\sum Y\right) / N=$ mean of all measured $Y$. When the mean $P$ for each specimen size are used as the data points, then $\omega_{Y \mid X}=0.0861$; see figure 8 . The values of $A, C$, $c_{0}, \omega_{Y \mid X}$ and of correlation coefficient $r_{c}$ are given in figures 7 and 8 . Note also that, according to figure $7 a$, linear elastic fracture mechanics would govern the behavior of specimens with $d / d_{a}=200$ or larger. This implies for concrete the beam depth of over $100 \mathrm{in}$. $(2.5 \mathrm{~m})$, and for mortar over $40 \mathrm{in} .(1.0 \mathrm{~m})$.
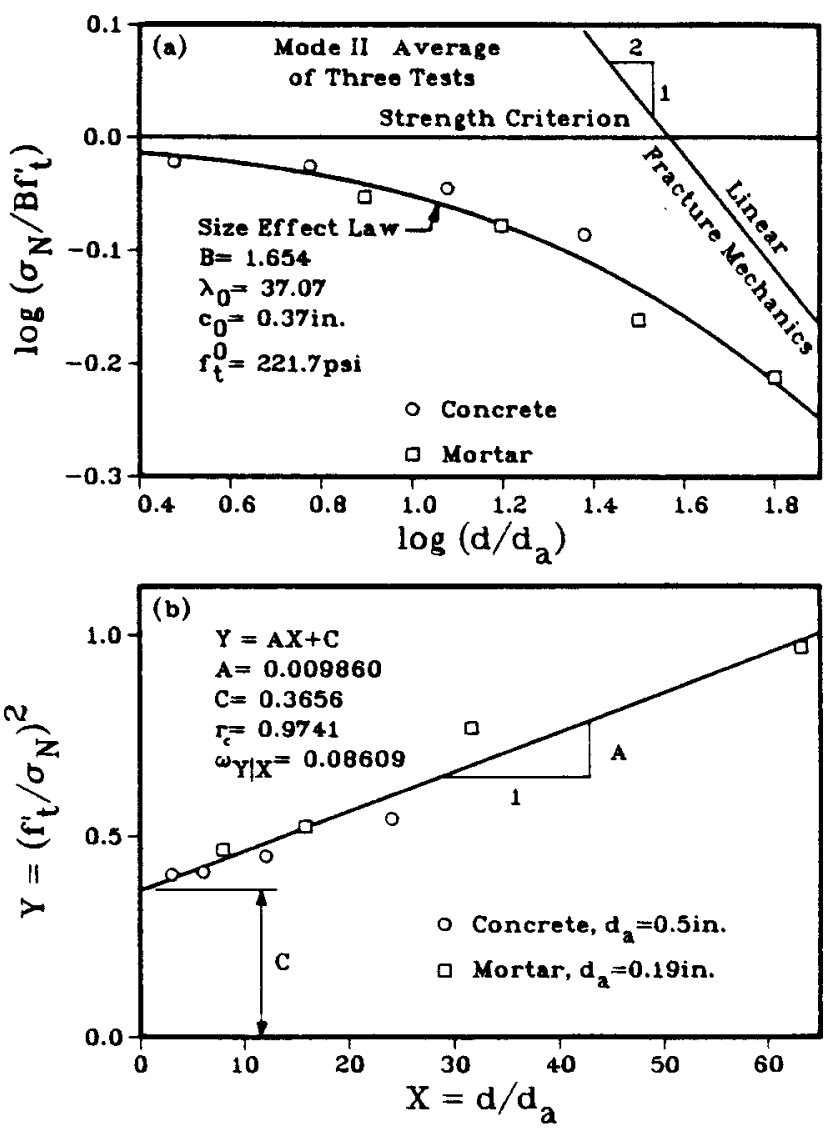

Fig. 8. - Mode II mean test results for shear fracture of concrete and mortar shown in the size effect plot and the transformed linear regreasion plot. 
Another advantage of the size effect law is that it provides the simplest way to determine the fracture energy $G_{f}$. As recently shown [14] :

$G_{f}=\frac{g\left(\alpha_{0}\right)}{A E_{c}}\left(f_{t}^{\prime}\right)^{2} d_{a}$

in which $A=$ slope of the size effect regression line ( fig. $7 b$ in the present case), $E_{c}=$ elastic Young's modulus, and $g\left(\alpha_{0}\right)=G\left(a_{0}\right) E_{c} b^{2} d / P^{2} ; \quad G(a)$ represents the linearly elastic energy release rate as a function of $a$ where $a=a_{0}+c, a_{0}=$ length of the notch and $c=$ length of the crack from the notch tip, $G\left(a_{0}\right)$ is the value of $G$ evaluated for $a=a_{0}, \alpha_{0}=a_{0} / d$ and $g\left(\alpha_{0}\right)$ is the nondimensional energy release rate. The values of $G\left(a_{0}\right)$ or $g\left(\alpha_{0}\right)$ can be found in handbooks [15] or textbooks ([3], [4], [5]) for many typical specimen geometries, however, not for the present specimen. Therefore, the value of $g\left(\alpha_{0}\right)$ was obtained by linear elastic finite element analysis; $g\left(\alpha_{0}\right)=2.93$.

Note that $f_{t}$ and $d_{a}$ are used in equation 3 because the regression plot in figures $7 b$ and $8 b$ is in nondimensional variables in order to allow comparing mortar and concrete. Alternatively, the regression could be done in the plot of $\sigma_{N}^{-2}$ versus $d$, and then $\mathrm{f}_{t}^{\prime 2}$ and $d_{a}$ would not appear in equation 3. For this reason, and because the slope of the regression line is the same in this plot, the precise values of $f_{t}$ (and $d_{a}$ ) matter only for $\lambda_{o}$ but are immaterial for the value of $G_{f}$ calculated in equation 3.

Regression of fracture data yields only the product $B f_{t}^{0}$ or $B f_{t}^{0}$, but not $B$ separately. To obtain $B, f_{t}^{0}$ must be determined independently. In absence of direct tensile test, the values $f$, were estimated from $\mathrm{ACI}$ formula $f_{t}^{\prime} \approx f_{t}^{A}=6 \sqrt{f_{c}^{\prime}}$ where $f_{c}^{\prime}$ was the measured compression strength of concrete and mortar used. Then $f_{t}^{0}$ was determined so that the sum of squares of the differences $f_{t}^{0}\left[1+\left(c_{0} / d_{a}\right)^{1 / 2}\right]-f_{t}^{A}$ for concrete and mortar be minimized.

Application of equation 3 to the present data yields the following values for Mode II fracture energy values :

$G_{f}=5.99 \mathrm{lb} / \mathrm{in}(1,049 \mathrm{~N} / \mathrm{m})$ for concrete,

$G_{f}=3.30 \mathrm{lb} / \mathrm{in}(578 \mathrm{~N} / \mathrm{m})$ for mortar.

A companion Mode I fracture test series, in which three-point bent specimens made of the same type of concrete and mortar were used, yields (again on the basis of equation 3) approximately the value $G_{f}=0.249$ $\mathrm{lb} / \mathrm{in}(43.6 \mathrm{~N} / \mathrm{m})$ for concrete and $G_{f}=0.131 \mathrm{lb} /$ in $(22.9$ $\mathrm{N} / \mathrm{m}$ ) for mortar. The linear regression plot and the size effect plot for the Mode I test is shown in figures 10 and 11 for the individual maximum load values and the mean load values, respectively. The maximum load values measured in Mode I are listed in table I.

It is now striking how much larger the fracture energy is for Mode II than it is for to Mode I. The ratio appears to be about 24 for concrete and 25 for
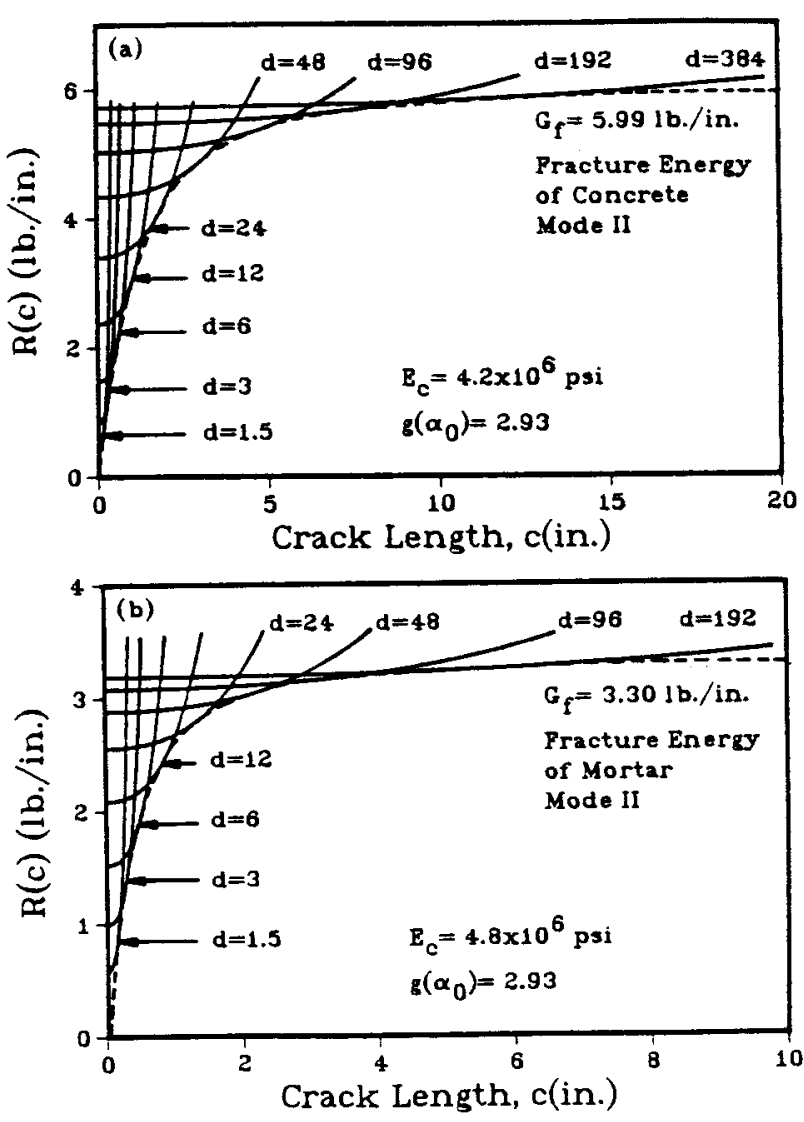

Fig. 9. - R-curve (Mode In constructed from maximum load data for specimens of various sizes.
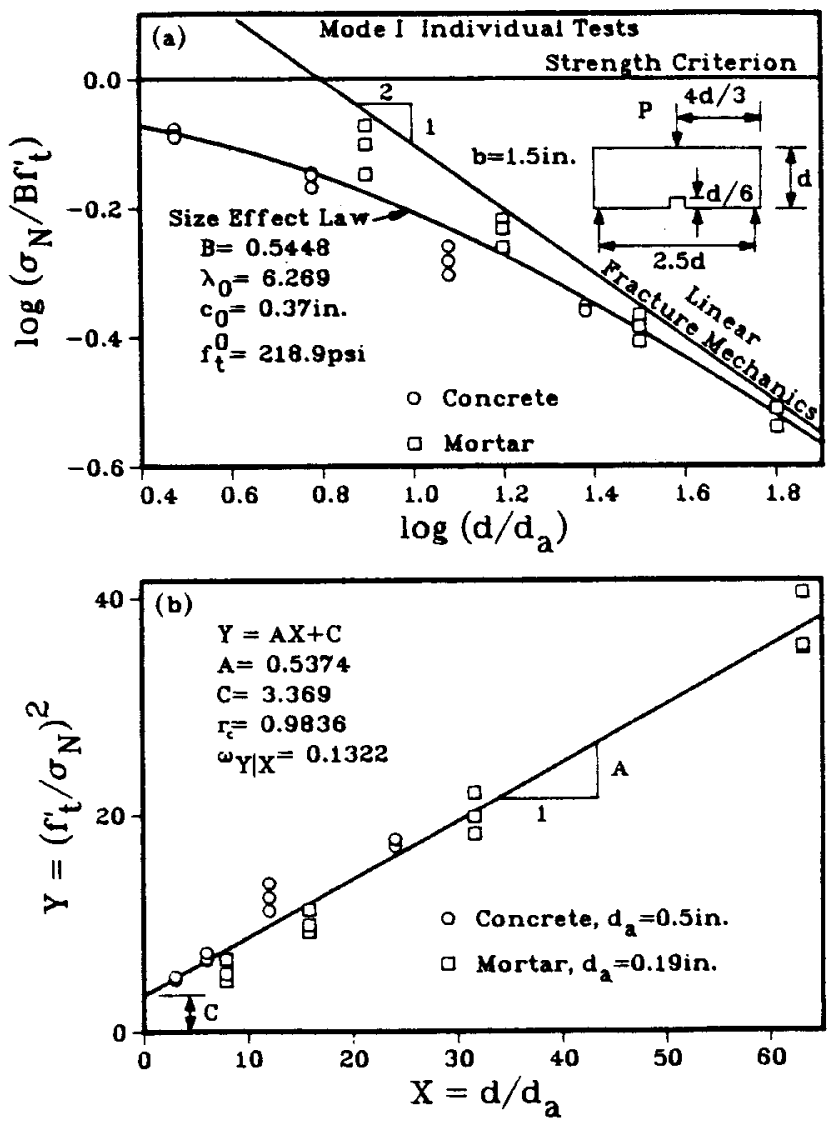

Fig. 10. - Mode I individual test results of concrete and mortar shown in the size effect plot and the transformed linear regression plot. 

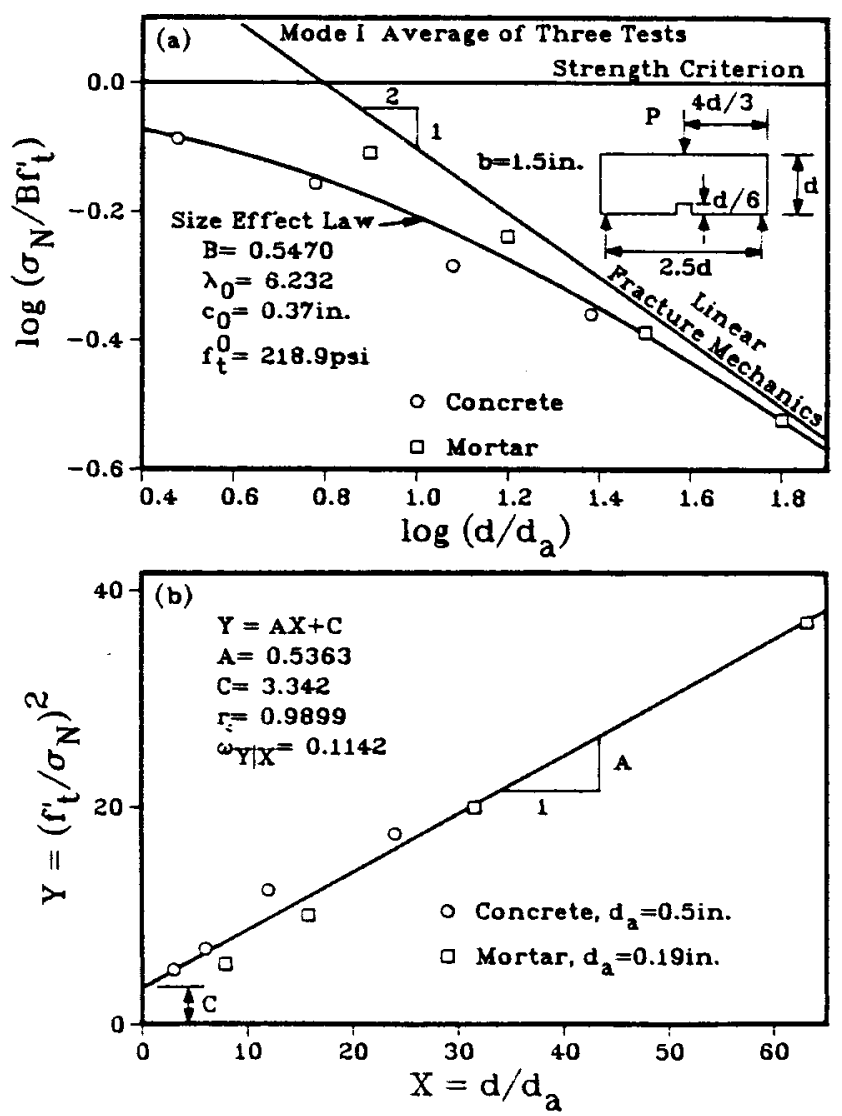

Fig. 11. - Mode I mean test results of concrete and mortar shown in the size effect plot and the transformed linear regression plot.

mortar. This huge difference seems, however, explicable in terms of the crack band finite element model [16] which was shown to also describe correctly the crack shear resistance [17]. It must be emphasized that the same material stress-strain relation [16] was used for both Mode I and Mode II finite element solutions. The results of calculations based on a rather simple, bilinear tensile stress-strain relation with strain softening [16] and compression crushing compare with the test results as follows:

Tests:

$G_{f}^{I}=0.249 \mathrm{lb} . / \mathrm{in} .(43.6 \mathrm{~N} / \mathrm{m}), G_{f}^{I I}=5.99 \mathrm{lb} . / \mathrm{in} .(1049 \mathrm{~N} / \mathrm{m})$.

Finite Elements:

$G_{f}^{I}=0.236 \mathrm{lb} . /$ in. $(41.3 \mathrm{~N} / \mathrm{m}), G_{f}^{I I}=5.70 \mathrm{lb} . / \mathrm{in} .(998 \mathrm{~N} / \mathrm{m})$.

Note, however, that while $G_{f}^{I}$ is a basic material constant, $G_{f}^{I I}$ is not since it may be calculated for a given specimen geometry on the basis of $G_{f}^{I}$, tensile and compression strengths and crack band width. The results would be different for a different specimen geometry, and we will return to this question at the end.

The pattern of cracking and the crack directions obtained by nonlinear finite element analysis according to the crack band model are shown in figure 13. The Mode I fracture energy is, according to the crack band model, represented by the area under the tensile stress strain diagram, multiplied by the width of the fracture
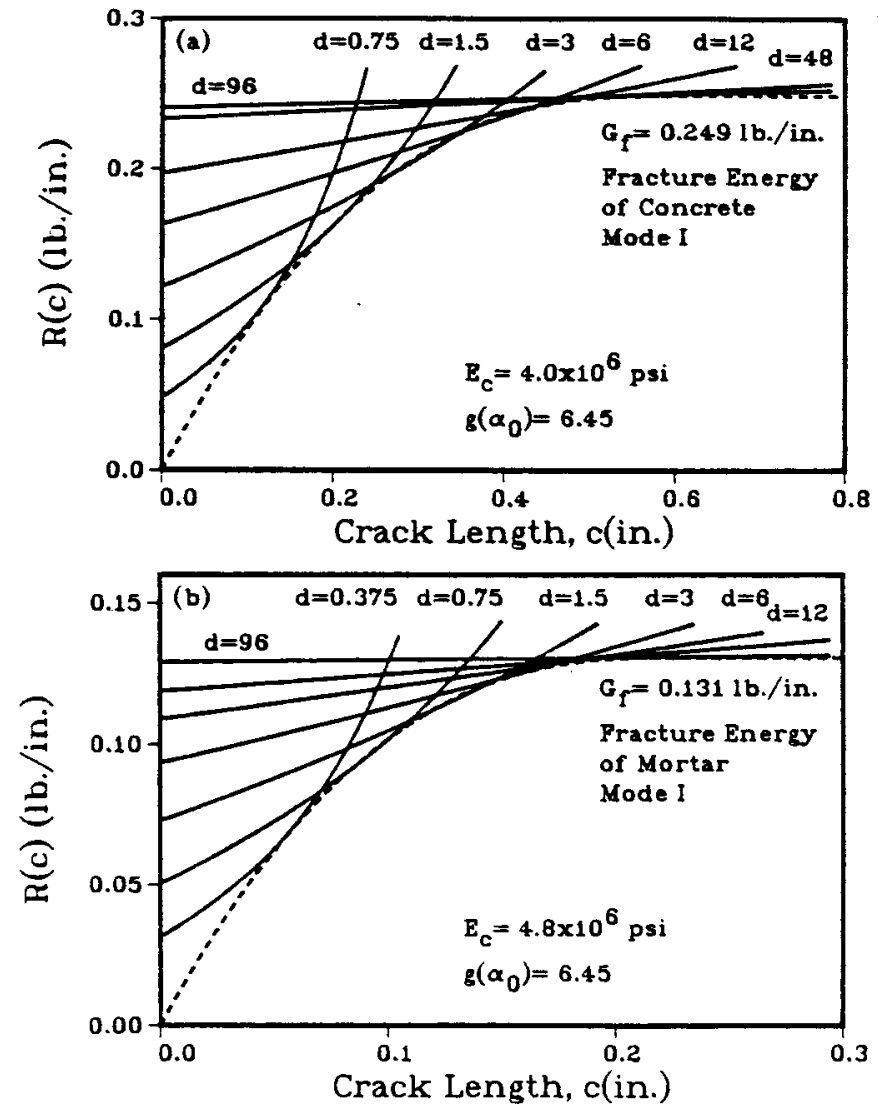

Fig. 12. - R-curve (Mode I) constructed from maximum load for specimens of various sizes.

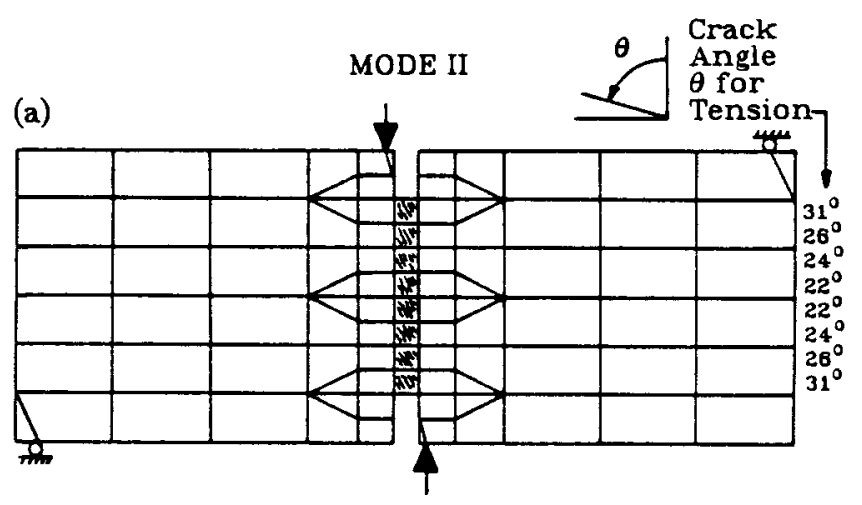

(b)

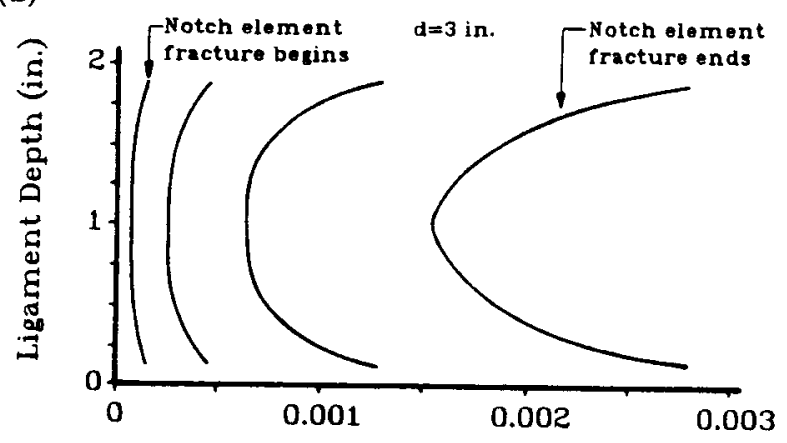

Principal Strain (in./in.)

Fig. 13. - Crack directions and principal stress distributions obtained by nonlinear analysis according to the crack band model. 
process zone. In Mode II (shear) fracture, tensile cracking is not all that is needed for shear failure. The cracks produced by shear are inclined about $31^{\circ}$, and a connection across the crack band remains after these cracks form; it consists of inclined struts of the material between the inclined cracks, spanning across the fracture ( fig. 6). The full shearing failure requires that these struts be crushed in compression. Therefore, the fracture energy for shear also includes energy obtained when the area under the compression stress-strain diagram for these inclined struts, including the strainsoftening portion of this diagram, is multiplied by the width of the fracture process zone. Now, the area under the complete compression stress-strain diagram is many times larger than the area under the complete tensile stress-strain diagram. Thus, it is not surprising that the $G_{f}^{\text {II }}$-values in equation 4 are far larger than those for Mode I fracture. It should be also noted that the compression resistance of the inclined struts gives at the same time a reasonable value for the shear resistance due to aggregate interlock (crack surface roughness) [17].

While the crack band model and the finite element models based on a stress-displacement relation for a line crack, such as Hillerborg's fictitious crack model ([18], [24]), or Willam's composite damage model [27], are essentially equivalent for Mode I fracture tests of concrete, there appears to be a significant difference for shear fracture. Both Mode I and Mode II fracture tests can be described with one and the same crack band model, but this is not true for the models based on the stress-displacement relation. For them some additional rule would apparently need to be added to make them work also for shear fracture and, in particular, represent the contribution of inclined strut crushing or surface roughness (aggregate interlock) to the shear fracture energy.

The size effect law makes it also possible to easily determine the $R$-curve, i.e., the plot of the energy, $R(c)$, required for crack growth as a function of the crack length, $c$ (measured from the notch tip). The conditions for crack propagation are $G(a)=R(c)$ and $\mathrm{d} G(a) / \mathrm{d} a=\mathrm{d} R(c) / \mathrm{d} c([3],[4],[14],[19])$. As shown in references [14] and [19], the $R$-curve represents the envelope of the fracture equilibrium curves of geometrically similar specimens of all sizes (see figs. 9 and 12), in which the convex curve for each specimen depth $d$ can be plotted on the basis of the measured maximum load value, $P([14],[19])$. It is essential to use for this purpose the maximum load values smoothed by the size effect law. If the use of unsmoothed, scattered data (as measured) is attempted, then the fracture equilibrium curves do not yield any envelope ([14], [19]). As already remarked, the limiting asymptotic value of the envelope, i. e., of the $R$-curve, is the fracture energy obtained from equation 3. Figure 9 shows the $R$-curve for shear fracture obtained after smoothing with the regression line in figure $7 b$, and figure 12 shows the $R$-curve for Mode I fracture calculated back from the regression line in figure $10 \mathrm{~b}$. A vailability of the $R$-curve makes it possible to approximately calculate failure loads of structures with an equivalent analysis based on linear elastic fracture mechanics, even though the fracture law is nonlinear.

\section{IMPERFECTIONS OF PRESENT TEST SPECIMENS}

The specimen used in the present tests (fig. 1) is not a perfect test specimen to measure Mode II fracture. The question arises whether a combination of Modes I and II takes place, and if so, whether the effect of Mode $I$ is significant.

To discuss the questions, consider first linear elastic fracture mechanics, which generally yieids acceptable approximations for the fracture of concrete despite its nonlinearity, provided that the variation of the energy required for crack growth is somehow determined separately. Under the assumption of linearity, the loading used in the present tests can be decomposed into symmetric and antisymmetric parts corresponding to fracture Modes I (tensile) and II (in-plane shear) (see fig. 14).
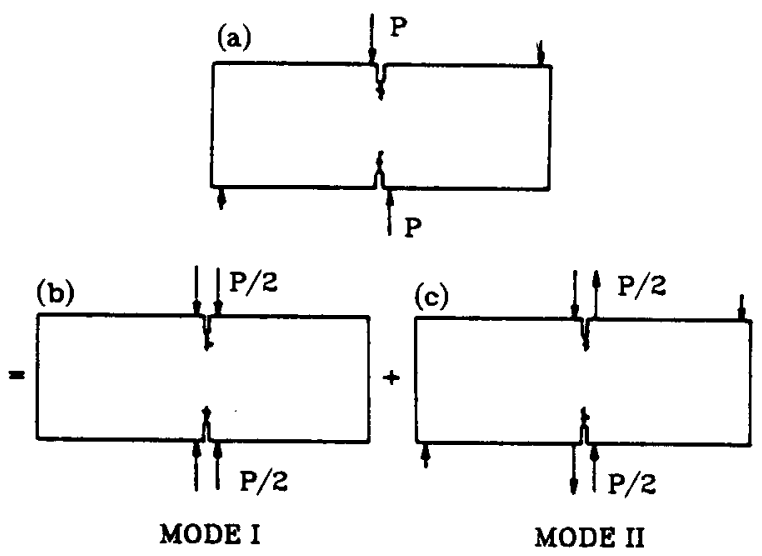

Fig. 14. - Decomposition of loading into symmetric and antisymmetric parts.

Ideally, the antisymmetric loading shown in figure 14 should be applied in the tests, however, it would be much more difficult to realize, due to the need to apply tensile loads on concrete and to control a proportional increase of a greater number of loads. Nevertheless, the superimposed symmetric loading ( fig. 14) should not prevent treating our specimen as approximately a Mode II fracture specimen, for the following reasons.

The loading in figure $14 b$, which bears much more similarity to the Brazilian tests than does the actual loading used ( $f$ ig. $14 a$ ), produces in the ligament section transverse normal stresses that are tensile in the middle and compressive near the notches, as is indicated by the result of linear elastic finite element analysis ( fig. 15). The symmetric loading produces a symmetric stress singularity at the tip of each of the notches or the cracks emanating from them. This singularity is characterized by nonzero Mode I stress intensity factor $K_{I}$. However, $K_{I}$ is negative because the transverse normal stresses near the notch or crack tips are 
compressive. Thus, a linearly elastic calculation indicates horizontal displacements which imply overlapping of the material on the cracks. Such overlapping is impossible, and instead of it compressive stresses are generated across the cracks. These stresses eliminate the singularity and cause that $K_{I}=0$ at the crack tip. Thus, there can be no Mode I fracture, and so the loading in figure $14 a$ cannot involve a combination of modes (combination of $K_{I}$ and $K_{I I}$ ) but a pure Mode II situation at the crack tip, same as does the antisymmetric loading in figure $14 \mathrm{c}$.

An exception to the preceding argument is the initial state at which the crack extension from the notch is zero. Since the notch has a finite width, material overlapping does not occur (except if the displacements are too large), and so a negative value of $K_{I}$ is possible for the symmetric loading part ( fig. 14b). However, this fact is irrelevant for the failure of the specimens tested, because the failure, i. e., the maximum load, did not occur right at the beginning of crack propagation but later, after a finite growth of the cracks from the notches.

According to linearly elastic fracture mechanics, there is no possibility for the cracks to begin in the middle of the ligament section rather than at the notches, because there is no stress singularity there.
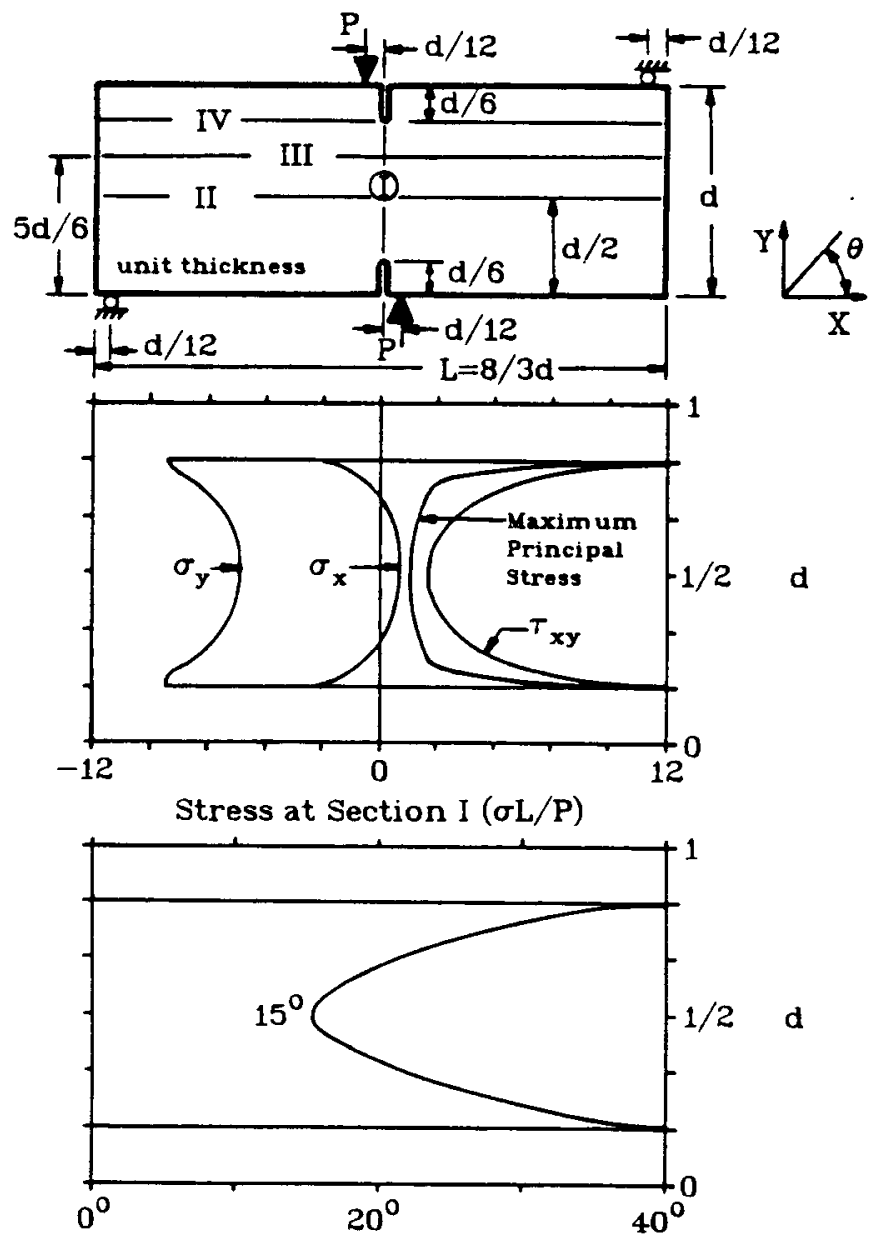

Principal Stress Direction at I $(\theta)$
Thus, as long as linear elastic analysis is adequate for the overall response of the specimen, tensile fracture can have no significant role in the failure.

This conclusion is also supported by linearly elastic finite element results based on elements larger than aggregate size which are too coarse to represent stress singularities. These results (fig. 15) indicate that the maximum principal stress, which is tensile near the notch or crack tip and occurs in a strongly inclined direction, is much larger in magnitude than the maximum principal stress (tensile) in the center of the ligament. Thus, the crack cannot be assumed to start at the center of the cross section but must initiate from the notch tips and propagate continuously toward the center. Now, as clearly seen from the tests, the cracks propagate straight along the ligament section rather than in strongly inclined directions from the notches, while the maximum principal tensile stress is strongly inclined. Thus, the cracks which begin at the notches cannot be considered as tensile. They represent shear cracks, although microscopically they may consist of a row of inclined tensile microcracks prior to the formation of the final continuous fracture.

More realistic finite element results can be obtained by nonlinear analysis based on the crack band theory, which has been shown to agree well with many different
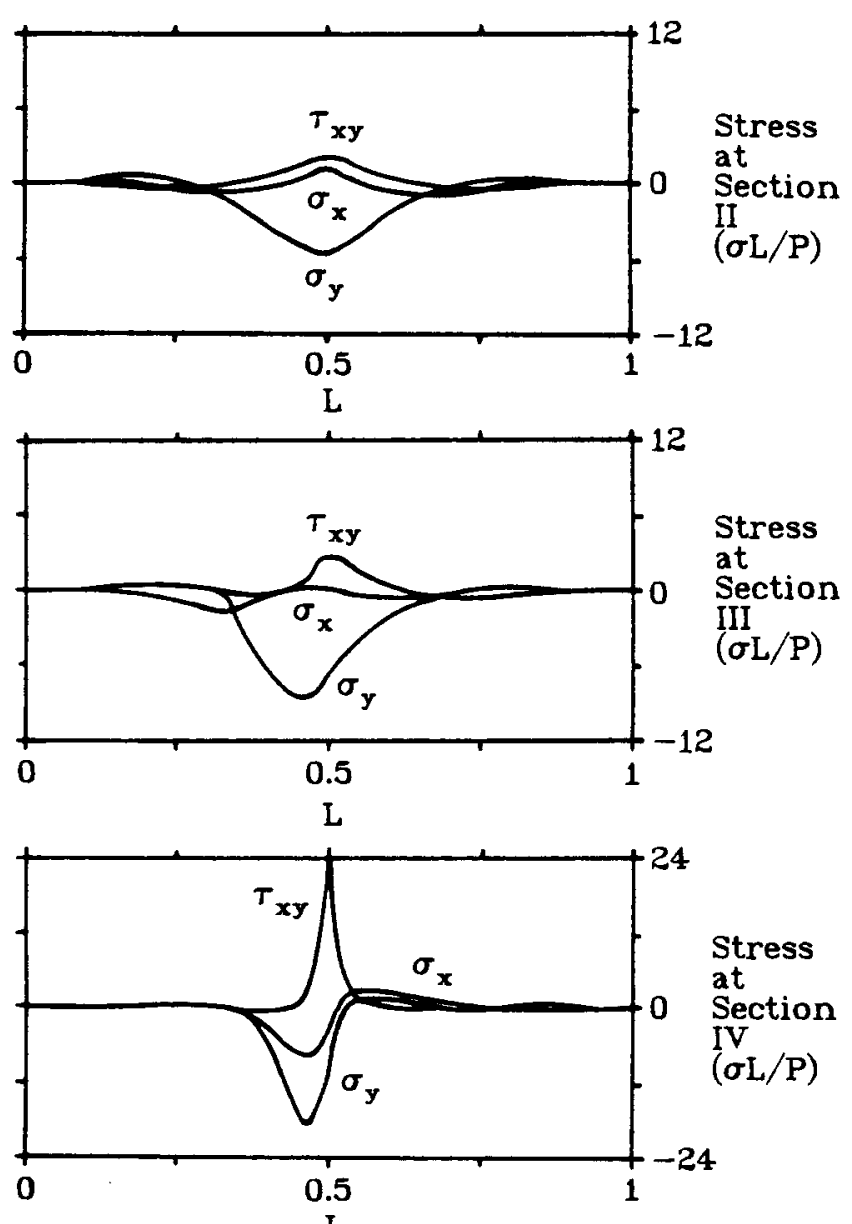

Fig. 15. - Results of linear finite element analysis 
types of fracture test data (see fig. 13). Although this analysis indicates a somewhat smaller inclination of the tensile microcracks than the linear elastic analysis, the inclination of these microcracks is still significant; $31^{\circ}$ as shown in figure 13. Thus, the band of microcracks emanating from the notches cannot be considered as tensile fracture but as shear fracture affected by tensile stresses. Furthermore, while the microcrack inclination near the notches is smaller than that from linear elastic analysis, the inclination obtained for the middle of the ligament section is larger $\left(22^{\circ}\right.$ in fig. 13). This indicates that even in the latest stage of failure, after the peak load, the overall fracture is not tensile.

Neither the linear nor the nonlinear finite element analysis based on the crack band theory permits the crack to initiate at the middle of the cross section. Thus, the horizontal tensile stresses which are produced at the middle of the ligament cannot be the cause of failure. In discussing a preliminary proposal for the present type of specimen [25], Ingraffea and Panthaki argued at a recent conference [28] that, due to the existence of horizontal tensile stresses at the middle of the ligament the specimen might be failing in Mode I, with the crack originating from the middle of the ligament, similarly to the Brazilian split cylinder test. However, from the preceding analysis it is clear that this is not the case. Another argument for dissimilarity from the Brazilian test is provided by the size effect, analysed in this paper. It was found that the maximum loads for geometrically similar specimens of different sizes agree quite well with the size effect law. This law can apply only for failures due to distributed fracturing (strain-softening) which do not involve any plastic dissipation (i. e., failure due to yield at constant stress). The nonlinear finite element analysis of the specimens used indicates no plasticized zones. In the Brazilian test, however, failure involves plastic deformation in wedgeshaped zones under the loads. Due to this additional plastic energy dissipation, the size effect in the Brazilian test cannot be as strong as indicated by the size effect law, but must be much weaker, especially for large specimens in which the zones of distributed cracking (strain-softening) localize into a smaller fraction of the total specimen volume. According to a private communication by Dr. Hasekawa and Dr. Shioya made at Shimizu Institute of Technology, Chiba, Japan, in May 1985, such a milder size effect, disappearing for larger size specimens, is indeed observed in the Brazilian test, but not in the present shear fracture tests.

\section{CONCLUSIONS}

1. Shear fracture (i. e., Mode II fracture) of concrete exists.

2. Like the tensile (Mode I) fracture, the shear (Mode II) fracture follows the size effect law of blunt fracture [11]. This implies that a large fracture process zone must exist at the fracture front, and that nonlinear fracture mechanics should be used, except possibly for extremely large structures.
3. The maximum aggregate size $d_{a}$ appears acceptable as a characteristic length for the size effect law. This further implies that the size of the fracture process zone at the maximum load is approximately a certain fixed multiple of the maximum aggregate size.

4. The $R$-curve for the shear fracture may be obtained from the size effect law as the envelope of all fracture equilibrium curves for geometrically similar specimens of various sizes.

5. The shear (Mode II) fracture energy for the present type of test appears to be about 25-times larger than the tensile (Mode I) fracture energy. This large difference may probably be explained by the fact that shear fracture energy includes not only the energy to create inclined tensile microcracks in the fracture process zone, but also the energy required to break the shear resistance due to interlock of aggregate and other asperities on rough crack surfaces behind the crack front.

6. The direction normal to the maximum principal stress cannot be considered, in general, as the direction of crack propagation in concrete. Rather, fracture seems to propagate in the direction for which the energy release rate from the entire structure is maximized.

7. The present test specimen does not undergo perfectly antisymmetric deformation. Nevertheless, the symmetric deformation component has apparently only a small disturbing effect because, in the sense of linear elastic fracture mechanics, the Mode I stress intensity factor is not positive. According to both linear and nonlinear finite element analysis, the maximum principal tensile stresses occur at the notches. So the cracks must originate also at the notches and propagate inward. This means that the fracture mode is essentially shear and that the effect of the transverse tensile strain at the middle of ligament cannot be significant.

\section{ACKNOWLEDGMENT}

Partial financial support under U.S. Air Force Office of Scientific Research Grant No. 83-0009 to Northwestern University is gratefully acknowledged. In the stage of evaluation of the test results, partial financial support has been also received from Reinforced Concrete Research Council.

\section{REFERENCES}

[1] Arrea M., Ingraffea A. R. - Mixed-mode crack propagation in mortar and concrete. Dept. of Structural Engineering, Corneil University, Report No. 81-13, 1982.

[2] BAŽANT Z. P., Estenssoro L. F. - Surface singularity and crack propagation. Int. J. of Solids and Structures, Vol. 15, 1979, pp. 405-426, Addendum Vol. 16, pp. 479-481.

[3] Broek D. - Elementary Engineering Fracture Mechanics. Sijthoff and Noordnoff, International Publishers, Netherlands, 1978.

[4] KNotT J. F. - Fundamentals of Fracture Mechanics. Butterworths, London, England, 1973.

[5] Rolfe S. T., BARsom J. M. - Fracture and Fatigue Control in Structures. Prentice-Hall, Englewood Cliffs, N. J., U.S.A., 1977. 
[6] Pfeiffer P. A. - Blunt crack band propagation in finite element analysis for concrete structures. Argonne National Laboratory, RAS 83-10, March 1983.

[7] Pfeiffer P. A., Marchertas A. H., Bažant Z. P. Blunt crack band propagation in finite element analysis for concrete structures. Transactions of 7 th International Conference on Structural Mechanics in Reactor Technology, SMiRT 7, Chicago, IL., Aug. 1983, Paper H5/2, North-Holland Publishing Co., Amsterdam, The Netherlands, pp. 227-234.

[8] Pan Y. C., Marchertas A. H., Kennedy J. M. - Finite element of a blunt crack propagation, modified J-integral analysis. Transactions of 7 th International Conference on Structural Mechanics in Reactor Technology, SMiRT7, Chicago, IL., Aug. 1983, Paper H5/3, NorthHolland, Publishing Co., Amsterdam, The Netherlands, pp. 235-292.

[9] Pan Y. C., Marchertas A. H., Pfeiffer P. A., Kennedy J. M. - Concrete cracking simulations for nuclear applications, Theoretical and Applied Fracture Mechanics, Vol. 2, No. 1, 1984, pp. 27-38.

[10] BAŽANT Z.P. - Fracture in concrete and reinforced concrete. Preprints, IUTAM Prager Symposium on "Mechanics of Geomaterials; Rocks, Concretes, Soils", Z. P. BAŽAnt Ed., Northwestern University, Sept. 1983, pp. 281-316.

[11] BAŽANT Z.P. - Size effect in blunt fracture: Concrete, rock metals. Journal of Engineering Mechanics, ASCE, Vol. 110, No. 4, April 1984, pp. 518-535.

[12] BaŽANT Z. P., Кıм J. K. - Size effect in shear failure of longitudinally reinforced beams. Journal of the American Concrete Institute, Vol. 81, No. 5, Sept.-Oct. 1984, pp. 456-468.

[13] BAŽANT Z. P. - Crack band model for fracture of geomaterials. Proc. 4th Intern. Conf. on Num. Meth. in Geomechanics, Z. EISENSTEIN Ed., held in Edmonton, Alberta, Vol. 3, 1982, pp. 1137-1152.

[14] Bažant Z.P., KIM J. K., Pfeiffer P. - Determination of nonlinear fracture parameters from size effect tests. NATO Advanced Research Workshop on Application of fracture mechanics to cementitious composites, S. P. SHAH Ed., held at Northwestern University, Sept. 4-7, 1984, pp. 143-169.

[15] TADA H., PARIS P. C., IRwIN G. R. - The stress analysis of cracks handbook. Del Research Corp., Hellertown, Pa., 1973.
[16] BaŽANT Z. P., OH B. H. - Crack band theory for fracture of concrete. Materials and Structures (RILEM, Paris) Vol. 16, 1983, pp. 155-177.

[17] BAŽANT Z. P., Gambarova P. G. - Crack shear in concrete: Crack band microplane model. Journal of Structural Engineering Division, ASCE, Vol. 110, No. ST9, Sept. 1984, pp. 2015-2035.

[18] Petersson P. E. - Crack growth and development of fracture zones in plain concrete and similar materials. Thesis presented to the Lund Institute of Technology, at Lund, Sweden, in 1981, in partial fulfillment of the requirements for the degree of Doctor of Philosophy.

[19] Bažant Z. P., KIM J. K., Pfeiffer P. - Nonlinear fracture properties from size effect tests. Journal of strctural Engineering, ASCE, in press.

[20] Wittmann F. H. Ed. - Fracture mechanics of concrete. Elsevier, Netherlands, 1983.

[21] Sin G. C., Sommer E., Dahl, W. Ed. - Application of fracture mechanics to materials and structures. Martinus Nijhoff, Boston, 1984.

[22] BAŽANT Z. P. Ed. - Mechanics of geomaterials: Rocks, concretes, soils. IUTAM Prager Symposium, Northwestern University, Evanston, Illoinois, sept. 1983, 664 p.

[23] Sнан S. P. Ed. - Application of fracture mechnics to cementitious composites. NATO Advanced Research Workshop, Sept. 4-7, 1984, Northwestern University.

[24] Hillerborg A., Modeer M. Petersson P. E. - Analysis of crack formation and crack growth in concrete by means of fracture mechanics and finite elements, Cement and Concrete Research, Vol. 6, 1976, pp. 773-782.

[25] Bažant Z. P., Pfeiffer P. A. - Tests of shear fracture and strain-softening in concrete. Proc. 2nd Symposium on the Interaction on non-nuclear munitions with structures. Panama City Beach, Florida, April 1985, pp. 15-19, P. Thompson Ed., Eglin Air Force Base.

[26] BAŽANT Z.P. - Effects of aggregate and structure sizes on concrete failure. Private Communication to $\mathrm{J}$. K. Kim, May 1985; also ACI Journal, Vol. 82, July 1985, pp. $579-583$.

[27] Willam K. - Experimental and computational aspects of concrete fracture. Proc. of International Conf. on Computer-Aided Analysis and Design of Concrete Structures, Split, Yugoslavia, Sept. 17-25, 1984, pp. 33-69.

[28] Ingraffea A. R., Panthaki N. J. - Analysis of shear fracture tests of concrete beams. Preprints, U.S. - Japan Seminar on Finite Element analysis of reinforced concrete structures, Tokyo, May 21-24, 1985, pp. 71-91.

\section{RESUME}

Essais de rupture en cisaillement du béton. - On a procédé aux essais en rupture d'échantillons de béton et de mortier à entailles symétriques dans le voisinage desquelles s'exerçaient des efforts concentrés qui ont déterminé une zone de concentration de contraintes de cisaillement. Les fissures à partir des entailles ne se sont pas propagées dans la direction normale à la contrainte maximale principale mais dans une direction où dominaient les contraintes de cisaillement. L'endommagement est donc dû d'abord à une rupture de cisaillement (Mode II). La direction de propagation des fissures paraît déterminée par le taux maximal de restitution d'énergie. Les essais de corps d'épreuve géométriquement similaires indiquent des charges maximales qui concordent avec la loi récemment établie de l'effet de dimension pour les ruptures qui étaient précédemment vérifiées pour les rup- tures en tension (Mode I). Ceci par la suite implique que l'énergie requise pour la croissance de fissure augmente avec l'extension de fissure à partir de l'entaille. Plus la fissure est loin de l'entaille, plus il faut d'énergie. La courbe de résistance que décrit ce phénomène se détermine à partir de l'effet de dimension. Celui-ci détermine également l'énergie de rupture en cisaillement qui se trouve être environ 25 fois supérieure à celle de la rupture en tension et concorder avec la valeur annoncée par le modèle de bande de fissure. Le corps d'épreuve de rupture est simple d'emploi mais pas parfaitement adapté à la rupture par cisaillement du fait que la déformation présente une composante symétrique avec la contrainte normale à travers le plan de fissuration. Néanmoins, les effets perturbateurs semblent être négligeables. Les résultats présentent de l'intérêt pour certains types de structures exposées à des charges concentrées sismiques d'impact et explosives. 